\title{
Recurrent Nodal Marginal Zone Lymphoma
}

National Cancer Institute

\section{Source}

National Cancer Institute. Recurrent Nodal Marginal Zone Lymphoma. NCI Thesaurus.

Code C4998.

The reemergence of nodal marginal zone lymphoma after a period of remission. 